Check for updates

The BMJ

Cite this as: $B M J$ 2021;372:n774 http://dx.doi.org/10.1136/bmi.n774 Published: 19 March 2021

\title{
Covid-19: AstraZeneca vaccine is not linked to increased risk of blood clots, finds European Medicine Agency
}

\section{Elisabeth Mahase}

The Oxford-AstraZeneca covid-19 vaccine is not linked to an increased risk of blood clots and is both safe and effective, an investigation by the European Medicine Agency (EMA) has concluded. ${ }^{1}$

The in-depth analysis of evidence-including laboratory results, clinical reports, autopsies, and clinical trial data-was carried out after a small number of blood clot cases (37) were reported in people who had received the vaccine. This led to 16 EU countries halting their vaccine rollout. ${ }^{2}$

"The committee has come to a clear scientific conclusion. This is a safe and effective vaccine," said Emer Cooke, EMA executive director, at a press conference on 18 March. "Its benefits in protecting people from covid-19 with the associated risks of death and hospitalisation outweigh the possible risks. The committee also concluded that the vaccine is not associated with an increase in the overall risk of thromboembolic events or blood clots."

Sabine Straus, chair of the Pharmacovigilance Risk Assessment Committee (PRAC), which conducted the investigation, added that the number of thromboembolic events reported after vaccination was "lower than the expected in the general population" and that there was "no evidence of a quality or batch issue."

"Moreover, because the vaccine is effective in preventing covid-19 disease, which in itself is a cause of blood clots, it likely reduces the risk of thrombotic events overall," she said.

Many countries are now set to resume rollout of the vaccine, including France, Germany, Italy, the Netherlands, Portugal, and Spain.

Specifically, the EMA said that seven cases of blood clots in multiple blood vessels and 18 cases of cerebral venous sinus thrombosis (blood clot in the brain's venous sinuses) had been reported as of 17 March. So far, more than seven million people in the EU and 11 million in the UK have been vaccinated with the AstraZeneca vaccine. About 100 ooo people develop blood clots every month in the EU, and 3000 cases a month are thought to occur in the UK.

\section{Continued investigation}

During the investigation a small number of cases of very rare but very serious clotting disorders were noted by the committee, which said it would continue investigating why these had occurred. Straus said, "PRAC will continue to gather more information on these conditions, including additional studies, and we'll keep them under very close monitoring."

In some very rare cases patients had a combination of thrombosis and thrombocytopenia and bleeding, while in others tiny clots developed in multiple blood vessels-a condition called disseminated intravascular coagulation.

The EMA has advised that information sheets on the vaccine for patients and healthcare professionals should be updated to include these possible very rare conditions to help them to spot potential signs and symptoms. It said that the clotting disorders could be the result of post-covid syndrome or linked to oral contraceptives. There have been widespread reports of covid-19 patients with blood clots and disseminated intravascular coagulation. ${ }^{3}$

Straus continued, "The PRAC review of the cases of thrombosis combined with thrombocytopenia-abnormally low levels of platelets-has shown a predominance in some groups and notably in women and younger women ... One of the risk factors that is highlighted for this disease or syndrome is indeed oral contraceptives. So that's also one of the things that we will be further investigating."

Research has shown that combined oral contraceptives can increase the risk of blood clots fourfold. ${ }^{4}$ However, Straus noted that this predominance could also be due to more young women being vaccinated and emphasised that different countries had prioritised different groups for vaccination.

"We are aware of cases described in the literature where young people who had had asymptomatic covid later on developed thrombotic and thromboembolic events," she explained. She added that, while the cases being investigated did not have an active infection, as confirmed by polymerase chain reaction tests, "it's still very possible that it might be something from the post-covid period.”

As well as the AstraZeneca vaccine, the EMA has said that it is looking at thrombotic events after people receive the other three covid-19 vaccines authorised in the EU-Pfizer, Moderna, and Johnson \& Johnson. Additionally, the agency is working with other regulators around the world to monitor the situation. It said that all vaccines currently being rolled out in the EU were reporting a similar number of blood clot cases.

European Medicines Agency. COVID-19 Vaccine AstraZeneca: benefits still outweigh the risks despite possible link to rare blood clots with low blood platelets. 18 Mar 2021. https://www.ema.europa.eu/en/news/covid-19vaccine-astrazeneca-benefits-still-outweigh-risks-despite-possible-linkrare-blood-clots.

2 Mahase E. Covid-19: WHO says rollout of AstraZeneca vaccine should continue, as Europe divides over safety. BMJ2021;372:n728. doi: 10.1136/bmj.n728 pmid: 33727218 
3 Merrill JT, Erkan D, Winakur J, James JA. Emerging evidence of a COVID-19 thrombotic syndrome has treatment implications. Nat Rev Rheumato/2020;16:581-9. doi: 10.1038/541584-020-0474-5. https://www.nature.com/articles/s41584-020-0474-5. pmid: 32733003

4 Stegeman BH, de Bastos M, Rosendaal FR, etal. Different combined oral contraceptives and the risk of venous thrombosis: systematic review and network meta-analysis. BMJ 2013;347:f5298. doi: 10.1136/bmj.f5298 pmid: 24030561

This article is made freely available for use in accordance with BMJ's website terms and conditions for the duration of the covid-19 pandemic or until otherwise determined by BMI. You may use, download and print the article for any lawful, non-commercial purpose (including text and data mining) provided that all copyright notices and trade marks are retained. 